\title{
Elucidating Mechanisms of Bladder Repair after Hyaluronan Instillation in Ketamine-Induced Ulcerative Cystitis in Animal Model
}

\author{
Yi-Lun Lee, ${ }^{* \dagger}$ Kun-Ling Lin, ${ }^{* \ddagger}$ Shu-Mien Chuang, ${ }^{\S}$ Yung-Chin Lee, ${ }^{\Phi \|}$ Mei-Chin Lu, ${ }^{* * \dagger \dagger}$ Bin-Nan Wu, ${ }^{\ddagger}$ Wen-Jeng Wu, ${ }^{* \Phi \|}$

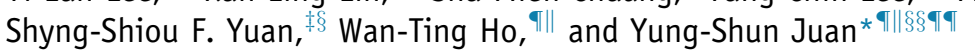

\begin{abstract}
From the Graduate Institute of Medicine* and the Department of Urology, ${ }^{\circledR}$ College of Medicine, the Translational Research Center, ${ }^{\S}$ Cancer Center, Department of Medical Research, and the Department of Pharmacology, ${ }_{\ddagger}^{\ddagger}$ School of Medicine, Kaohsiung Medical University, Kaohsiung; the Department of Urology, ${ }^{\dagger}$ Sinying Hospital, Ministry of Health and Welfare, Tainan; the Departments of Obstetrics and Gynecology and Urology, ${ }^{\ddagger}$ Kaohsiung Medical University Hospital, Kaohsiung; the Graduate Institute of Marine Biotechnology, ** National Dong Hwa University, Pingtung; the National Museum of Marine Biology \& Aquarium, ${ }^{\dagger \dagger}$ Pingtung; the Department of Urology, ${ }^{\S \S}$ Kaohsiung Municipal Ta-Tung Hospital, Kaohsiung; and the Department of Urology, " Kaohsiung Municipal Hsiao-Kang Hospital, Kaohsiung, Taiwan
\end{abstract}

\author{
Accepted for publication \\ June 1, 2017. \\ Address correspondence to \\ Yung-Shun Juan, M.D., Ph.D., \\ Department of Urology, Kaoh- \\ siung Medical University Hos- \\ pital, 100 Shih-Chuan 1st Rd., \\ Sanmin District, Kaohsiung \\ 807, Taiwan. E-mail: \\ juanuro@gmail.com.
}

\begin{abstract}
Ketamine-induced ulcerative cystitis (KIC) initially damaged the bladder mucosa and induced contracted bladder thereafter. Hyaluronan (hyaluronic acid; HA) instillation to the bladder has been used to treat KIC. The present study investigated bladder injury by urothelial defect and HA degeneration and bladder repair by urothelium proliferation and differentiation. This work was based on the hypothesis that HA treatment altered the bladder urothelial layer and the expression of hyaluronan-metabolizing enzymes and/or HA receptors in KIC. Cystometrogram study and tracing analysis of voiding behavior revealed that the ketamine-treated rats exhibited significant bladder hyperactivity with an increase in micturition frequency and a decrease in bladder capacity. The expression of inflammatory and fibrosis markers was also increased in the ketamine-treated group. Moreover, ketamine administration decreased the expression of urothelial barrier-associated protein, altered HA production, and induced abnormal urothelial differentiation, which might attribute to urothelial lining defects. However, HA instillation ameliorated bladder hyperactivity, lessened bladder mucosa damage, and decreased interstitial fibrosis. HA instillation also improved the level of HA receptors (CD44, Toll-like receptor-4, and receptor for HAmediated motility) and $\mathrm{HA}$ synthases 1 to 3 and decreased the expression of hyaluronidases in the urothelial layer of bladder, resulting in enhanced mucosal regeneration. These findings suggested that HA could modulate inflammatory responses, enhance mucosal regeneration, and improve urothelial lining defects in KIC. (Am J Pathol 2017, 187: 1945-1959; http://dx.doi.org/10.1016/j.ajpath.2017.06.004)
\end{abstract}

Ketamine is a dissociative anesthetic, which has recently been increased in nonmedical usage linked with the growth of dance culture. More and more reports showed that ketamine abuse not only affected brain and cardiovascular system but also damaged the urinary tract function. The symptoms and signs associated with ketamine-induced ulcerative cystitis (KIC) include frequency, dysuria, and hematuria. Urodynamic examination revealed a significant decrease of bladder capacity and detrusor overactivity. Clinical observation showed that KIC occurred initially in the bladder mucosa and induced interstitial fibrosis thereafter. In the clinical setting, antibiotics, nonsteroidal anti-inflammatory drugs, steroids, and anticholinergic drugs are used for relieving these lower urinary tract symptoms, but the effectiveness is limited. ${ }^{1}$ The symptoms of KIC are similar to interstitial cystitis (IC). ${ }^{2}$ Therefore, treatments

\footnotetext{
Supported by the Ministry of Health and Welfare Executive Yuan MOHW103-TD-B-111-05 (Y.-L.L.), Department of Medical Research, Kaohsiung Medical University Hospital grants KMUH101-1R43 (Y.-S.J.), KMUH 103-3R42 (Y.-S.J.), KMUH 104-4R45 (Y.-S.J.), and KMUH 1044M30 (K.-L.L.), and Kaohsiung Municipal Hsiao-Kang Hospital grants Kmhk102-022 (Y.-S.J.), Kmhk-103-021 (Y.-S.J.), and Kmhk-104-021 (Y.-S.J.).

Y.-L.L. and K.-L.L. contributed equally to this work.

Disclosures: None declared.
} 
with intravesical instillation of hyaluronic acid (HA) and oral pentosan polysulfate were also used for KIC patients to relieve the symptoms of lower urinary tract symptoms. ${ }^{1-3}$

There are at least three layers in the bladder urothelium, including the basal layer attached to a basement membrane, the intermediate layer, and the superficial layer composed of umbrella cells that maintain the urothelial barrier. ${ }^{4}$ Tight junction proteins between the superficial umbrella cells are composed of multiple proteins such as occludins and claudins. These proteins, along with uroplakins (UPKs) in the superficial layer, contribute to the urothelial barrier function. ${ }^{5-7}$ Bladder urothelial glycosaminoglycan (GAG) layer covers the umbrella cells in the superficial layer, and the main components of GAG include HA, chondroitin sulfate, and heparan sulfate. They contribute to urothelial barrier functions against toxic substances, carcinogens, and microorganisms from the urine. ${ }^{8}$ GAG layer replenishment therapy is widely performed for patients with IC/bladder pain syndrome (BPS) who have a poor response to conventional therapy. ${ }^{9}$ However, the mechanisms that underlie such impermeability are less known. ${ }^{10}$

Urothelial integrity is maintained through a complex process of migration, proliferation, and differentiation. ${ }^{11}$ Urothelial cells in the basal layer have stem cell-like properties, exhibiting slow proliferative rates. ${ }^{12,13}$ However, in various bladder inflammatory conditions, urothelial cells can accelerate its proliferation. For example, when damaging the umbrella cell layer with cytotoxic agents (protamine sulfate and cyclophosphamide), the urothelium can rapidly undergo both functional and structural changes to restore the barrier function in response to injury. ${ }^{14-16}$ In the early stages of restoration after disruption of the barrier, the superficial urothelium may appear smaller in size and often covered with microvilli. ${ }^{14}$

HA regulates various cellular activities from migration, proliferation, differentiation, and inflammation to cell-cell interactions and cell-extracellular matrix adhesions. ${ }^{17}$ Some studies have also implicated that HA is involved in wound healing, tissue repair, and regeneration and in angiogenesis. ${ }^{17-20}$ In addition, HA plays the role of a negative regulator in inflammatory activation and protector of cells against free radical damages. ${ }^{21}$ Although mesenchymal cells are believed to be the predominant source of $\mathrm{HA},{ }^{22} \mathrm{HA}$ can be released by many cell types. ${ }^{20,22-24}$ There were reports that HA regulated cell proliferation, differentiation, and migration through interactions with HA synthases (HAS1 to HAS3), hyaluronidases [HYAL1 to HYAL4 and sperm adhesion molecule (PH20)], and HA receptor, including CD44, receptor for HA-mediated motility (RHAMM), and Toll-like receptor (TLR)-4. ${ }^{25-28}$ In the collagen-induced arthritis model, inhibition of HYAL expression and hyaluronan degradation with specific siRNAs for HYAL1 to HYAL3 were found to significantly reduce CD44 expression and proinflammatory cytokines in mouse synovial fibroblasts. ${ }^{29}$ Moreover, the degraded hyaluronan fragments were reported to play an important role in inflammation, cell proliferation, and wound healing through their antioxidant properties and interaction with CD44, RHAMM, and TLR-4 receptors. ${ }^{30-32}$

Despite the above progresses, there is a lack of investigations that explore the changes in the hyaluronan pathway after KIC. In our previous study, ketamine-treated rats were found to show bladder hyperactivity accompanied by urothelial tight junction disruption and increases in the expression of apoptosis-associated proteins. ${ }^{33}$ In considering the importance of hyaluronan metabolism in maintaining the integrity of bladder structure, function, and tissue repair, the present study hypothesized that HA treatment might alter the expression of hyaluronan-metabolizing enzymes and receptors and therefore improve bladder repair in KIC. Accordingly, the expression of these enzymes and receptors involved in HA synthesis and degradation in pathologic processes were investigated in KIC after ketamine and/or HA treatment.

\section{Materials and Methods}

\section{Animals and Ketamine Administration}

Experiments were performed on 50 adult female SpragueDawley rats (Animal Center of BioLASCO, Taipei, Taiwan) that weighed between 200 and $250 \mathrm{~g}$. Sprague-Dawley rats were divided into four groups, including i) the control group, with i.p. $0.9 \%$ saline daily injection for 4 weeks; ii) the ketamine group, with ketamine (Ketalar; $30 \mathrm{mg} / \mathrm{kg}$; Pfizer, New York, NY) daily i.p. injection for 4 weeks; iii) the ketaminerecovery group, with ketamine daily injection for 4 weeks and then allowed recovery for 2 weeks; and iv) the ketamine-HA group, with ketamine daily injection for 4 weeks and then daily intravesical instillation with HA solution (Cystistat; $1.6 \% \mathrm{w} / \mathrm{v}, 800 \mathrm{mg} / 50 \mathrm{~mL}$; Mylan, Canonsburg, PA) for 2 weeks. A sterile solution of HA was administered by urethral catheter (PE50 tube), and the instillation $0.5 \mathrm{~mL}$ was retained for 30 minutes. Rats were weighed once at the beginning of every week for adjusting the amount of ketamine to be administered. This study was approved by the Animal Care and Treatment Committee of Kaohsiung Medical University. All experiments were conducted according to the guidelines for laboratory animal care. All efforts were made to minimize animal stress/distress.

\section{Isovolumetric Cystometrogram}

Sprague-Dawley rats were anesthetized with Zoletil-50 (1 $\mathrm{mg} / \mathrm{kg}$, i.p. injection). After the bladder was emptied, the urethral catheter was placed to fill the bladder and infuse with saline at a steady rate $(0.08 \mathrm{~mL} / \mathrm{min})$ to measure the bladder pressure. ${ }^{33,34}$ Pressure and force signals were amplified (ML866 PowerLab; ADInstruments, Colorado Springs, CO), recorded on a chart recorder, and digitized for computer data collection (Labchart 7, Windows 7 system; ADInstruments). Cystometrogram parameters, including the 
filling pressure, the peak micturition pressure, the frequency of nonvoiding contractions (contraction without urine leakage during infusion), and the bladder capacity, were recorded.

\section{Metabolic Cage Study for Micturition Pattern}

After treatment, rats were placed in individual metabolic cages (R-2100; Lab Products, Rockville, MD). The 24-hour micturition frequency and voided volume were determined using a cup fitted to a transducer (MLT 0380; ADInstruments). Finally, the 24-hour volume of urine output and water intake was measured and recorded.

\section{Ketamine Metabolites Assay in Urine and Serum}

Rat blood was separated by centrifugation at $4^{\circ} \mathrm{C}$ for examining ketamine and its metabolite norketamine. The urine was collected by the metabolic cage on the day before euthanizing the animal. The concentrations of urine and serum ketamine and norketamine were determined by using the highperformance liquid chromatography. ${ }^{35}$ After extraction and purification, samples underwent chromatography on a reversed-phase column, and ketamine and norketamine were detected at $200 \mathrm{~nm}$ by UV spectrophotometry. This study was performed according to ISO 9001:2000 requirements.

\section{Histologic Study by Masson's Trichrome Stain}

Experimental rats were perfused with saline solution, and the bladders were removed. The bladders were embedded in paraffin blocks, and serial sections of 5- $\mu \mathrm{m}$ thickness were obtained. Deparaffinized sections were stained with Masson's trichrome stain (Masson's Trichrome Stain Kit; Dako, Glostrup, Denmark). The Masson's trichrome staining was used to stain connective tissue in blue and detrusor smooth muscle in red. ${ }^{33,34}$ The stained images of bladder were captured by digital camera in 10 random, nonoverlapping frames at $\times 400$ magnification.

\section{Real-Time Quantitative PCR Analysis}

The bladder was separated to obtain urothelial layer (UL) and suburothelial layer (SL). The bladder mucosa (UL) was gently scraped from the underlying stroma (SL) and the muscular layer (ML), using forceps by hands under dissecting microscope. Occasionally, the mucosa might mix with a little stromal tissue, but it was carefully separated. Real-time quantitative PCR was analyzed to explore the mRNA expression of HA receptors (CD44, RHAMM, and TLR-4), HAS1 to HAS3, and HYALs (HYAL1 to HYAL4 and PH20) in the bladders. SYBR Green I kit (TaKaRa Biotechnology, Kusatsu, Shiga, Japan) was performed, and all of the primers are listed in Table 1. The products generated for primers were examined, and the relative

Table 1 Primer Sequences Used in Real-Time Quantitative PCR

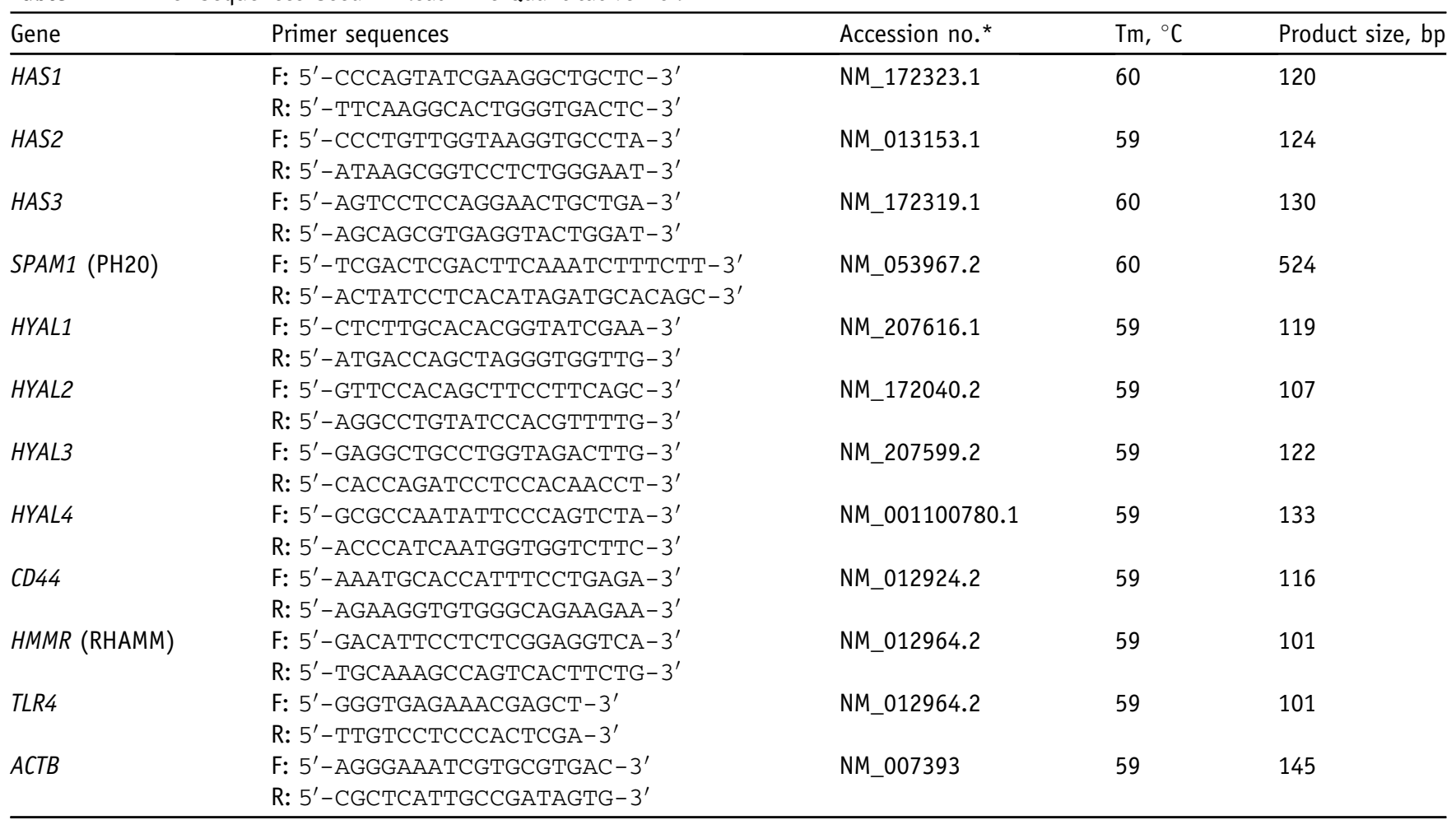

*Available at https://www.ncbi.nlm.nih.gov/nuccore.

F, forward; R, reverse; Tm, temperature. 
expression levels of targeted genes were normalized by $\beta$-actin by using the DDCT comparative method. ${ }^{36} \mathrm{~A}$ total of eight samples for each group were used, and each sample was run in triplicate.

\section{Immunofluorescence Studies for Bladder Proteins}

Immunostaining study was performed according to a previously published method. ${ }^{37,38}$ The bladder sections were double stained with the primary antibody to claudin-4 (mouse monoclonal IgG1; dilution 1:100; Invitrogen, Camarillo, CA), E-cadherin (rabbit polyclonal IgG; dilution 1:100; Proteintech, Chicago, IL), CD44 (mouse monoclonal IgG1; dilution 1:100; Cell Signaling, Danvers, MA), TLR-4 (mouse monoclonal IgG2b; dilution 1:1000; Abcam, Cambridge, MA), RHAMM (rabbit polyclonal IgG; dilution 1:1000; GeneTex, Irvine, CA), cytokeratin (CK)14 (rabbit polyclonal IgG; dilution 1:250; GeneTex), and CK17 (mouse monoclonal IgG2b; dilution 1:10; Novus, Littleton, $\mathrm{CO})$ at $4{ }^{\circ} \mathrm{C}$ overnight and then incubated with secondary antibody (dilution 1:800; Invitrogen) conjugated to fluorescein isothiocyanate for claudin-4 and CD44 and conjugated to rodamine for E-cadherin and CK14. In each experiment, negative controls without the primary antibody were performed to elucidate nonspecific immunostaining.

\section{Protein Isolation and Western Blot Analysis}

According to the previously described method, ${ }^{39}$ the separated bladder mucosa (UL), the underlying stroma (SL), or the ML, using forceps by hands under dissecting microscope, were homogenized on ice in the buffer $(50 \mathrm{mmol} / \mathrm{L}$ Tris, $\mathrm{pH} 7.5,5 \%$ Triton X-100) containing the halt protease inhibitor cocktail (Pierce, Rockford, IL) at $100 \mathrm{mg} / \mathrm{mL}$. Protein $(30 \mu \mathrm{g})$ from the bladders was loaded on SDS-PAGE gels and transferred to polyvinylidene fluoride membranes (Immobilon-P; Millipore, Billerica, MA). Immobilon-P (Millipore) membranes were incubated with primary antibodies to inflammatory and fibrosis markers [cyclooxygenase (COX)-2, transforming growth factor (TGF)- $\beta 1$, fibronectin, and collagen I], tight junction proteins [claudin-4 and zonula occludens (ZO)-1], proliferation marker (Ki-67), differentiated urothelial marker (UPKIII and CK14), adhesion protein (E-cadherin), and HA receptors (CD44, TLR-4, and RHAMM). The specifications of these markers were described as follows: COX-2 (mouse monoclonal IgG; dilution 1:1000; Cayman, Ann Arbor, MI), TGF$\beta 1$ (mouse monoclonal IgG1; dilution 1:500; R\&D Systems, Minneapolis, MN), fibronectin (mouse monoclonal IgG1; dilution 1:1000; BD Diagnostics, Sparks, MD), type 1 collagen (rabbit polyclonal IgG; dilution 1:1000; Abcam), claudin-4 (mouse monoclonal IgG1; dilution 1:1000; Invitrogen), ZO-1 (rabbit polyclonal IgG; dilution 1:1000; Thermo, Waltham, MA), Ki-67 (rabbit monoclonal IgG; dilution 1:1000; Abcam), UPKIII (mouse monoclonal IgG1; dilution 1:1000; Abcam), CK14 (rabbit polyclonal IgG; dilution 1:1000; GeneTex), E-cadherin (rabbit polyclonal IgG; dilution 1:1000;
Proteintech), CD44 (mouse monoclonal IgG1; dilution 1:1000; Cell Signaling), TLR-4 (mouse monoclonal IgG2b; dilution 1:1000; Abcam), and RHAMM (rabbit polyclonal IgG; dilution 1:1000; GeneTex). The obtained results were normalized with $\beta$-actin (mouse monoclonal IgG1; dilution 1:1000; Millipore) and glyceraldehyde-3-phosphate dehydrogenase (mouse monoclonal IgG1; dilution 1:1000; Millipore).

\section{Statistical Analysis}

Analysis of variance was conducted for the above experiments, followed by the Bonferroni test and two-way analysis of variance for individual comparison. The means $\pm \mathrm{SD}$ and $P$ values were calculated on triplicate experiments. The $t$-test was applied for calculating $P$ values for comparison. The significant level was set at a $P<0.05$.

\section{Results}

Physical Characteristics, Biochemical Parameters, Cystometric Parameters, and Voiding Behavior of Ketamine-Associated Bladder Damage

\section{Physical Characteristics}

The physical characteristics are shown in Table 2, including body weight, bladder weight, water intake, and urine output. After 4 weeks of ketamine treatment, no significant differences were found in body weight, water intake, and urine output between the control and the ketamine groups. However, there was a significant increase in bladder weight in the ketamine group compared with the control group.

Concentrations of Ketamine and Its Metabolites in Urine and Serum

The concentrations of ketamine and norketamine in serum and urine are also shown in Table 2. In the control group, the serum and urine concentrations of ketamine and norketamine were undetectable. In contrast, the concentrations of urine ketamine and norketamine in the ketamine group were $1668.0 \pm 225.6 \mathrm{ng} / \mathrm{mL}$ and 29,720.2 $\pm 1261.7 \mathrm{ng} / \mathrm{mL}$, respectively. Moreover, serum concentrations of ketamine and norketamine were also undetectable in the ketaminerecovery and the ketamine-HA groups. In addition, the ratio of urine protein to creatinine as calculated to evaluate renal function showed a significant increase in the ketamine group compared with the control group. The data demonstrated that the toxic effect in the urinary bladder was derived from not only ketamine but also its primary metabolite, norketamine.

\section{Bladder Function and Voiding Behavior}

The urodynamic parameters and representative tracings, including micturition frequency, micturition pressure, voided volume, and voided contraction between micturition are shown in Table 2 and Figure 1. Ketamine treatment increased bladder overactivity with increases in peak micturition pressure, frequency, voiding contraction, and 
Table 2 Physical Characteristics, Biochemistry, and Urodynamic Parameters for Different Experimental Groups

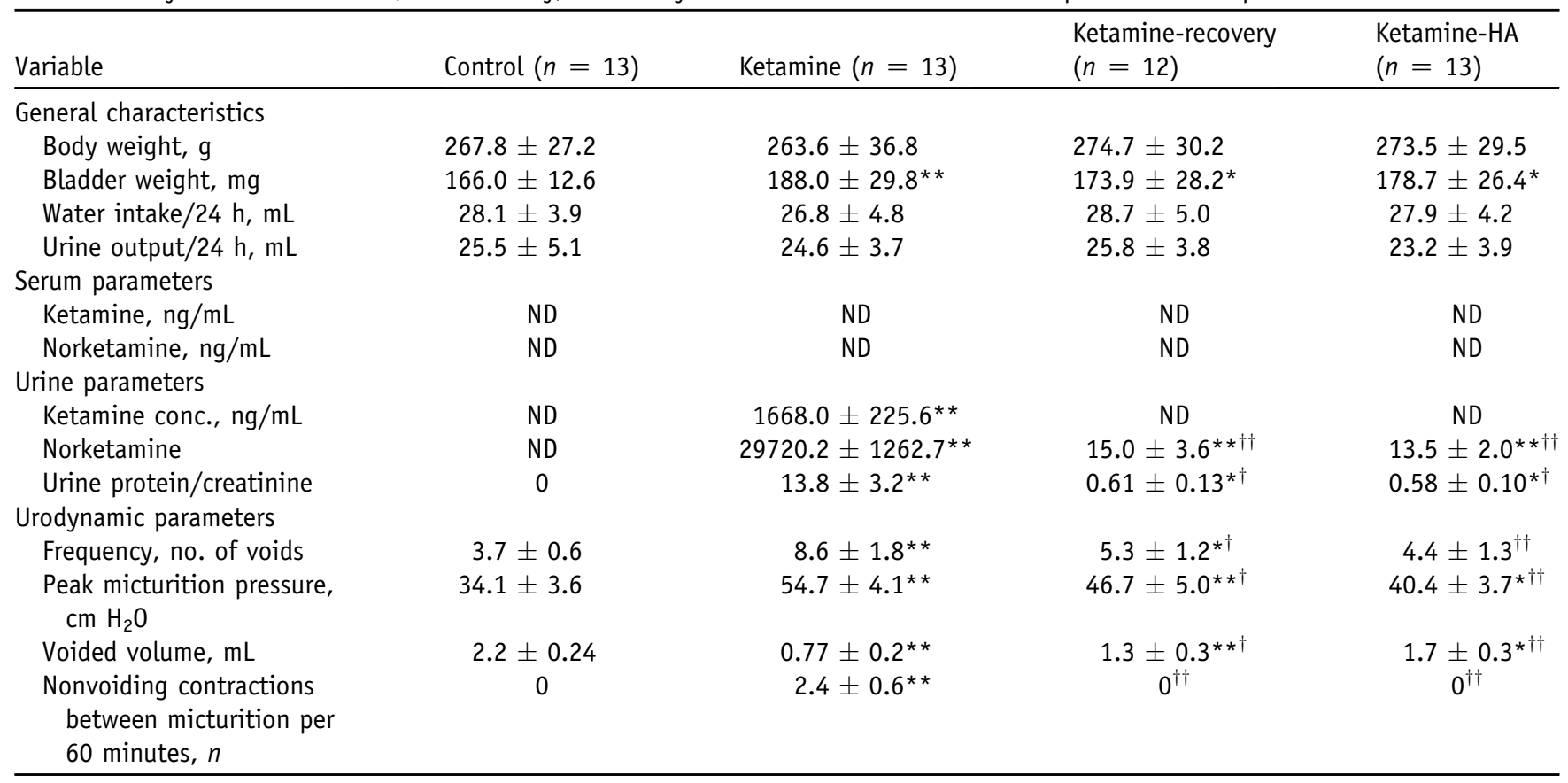

Data are expressed as means \pm SD.

${ }^{*} P<0.05,{ }^{* *} P<0.01$ versus control; ${ }^{\dagger} P<0.05 ;{ }^{\dagger} P<0.01$ versus the ketamine group.

Conc., concentration; HA, hyaluronic acid; ND, not detected.

nonvoiding contraction (Figure 1A). Significant increases were found in micturition frequency (2.3-fold) and nonvoiding contraction frequency and peak micturition pressure (1.6-fold) compared with the control group. Furthermore, the tracing analysis of voiding behavior using metabolic cages revealed an enhancement in micturition frequency and a decrease in voiding volume in the ketamine group compared with the control group (Figure 1B and Table 2). Similarly, cystometrogram study and tracing analysis of voiding behavior showed that the ketamine-recovery group also enhanced micturition frequency (1.4-fold) and micturition pressure (1.4-fold) but reduced voiding volume (0.6-fold) compared with the control group (Figure 1 and Table 2). However, treatment with HA significantly decreased voiding pressure and nonvoiding contractions; however, the voiding pattern was similar to that in the control group. These findings demonstrated that the ketamine-treated rats exhibited significant bladder hyperactivity, abnormal detrusor activity with an increase in micturition frequency, and bladder storage dysfunction. In contrast, the administration of HA improved bladder hyperactivity and damage.

\section{HA Improves Ketamine-Induced Alterations in Bladder Histologic Feature and Urothelial Junction-Associated Protein Expression}

Masson's trichrome stain was performed to investigate the pathologic changes in the bladder after treatments (Figure 2).
In the control group (Figure 2A), the UL has three to five layers, and sparse collagen was distributed in the SL. On the contrary, in the ketamine group (Figure 2B), there were significant denuded and defective urothelial mucosa in the UL and mononuclear cell infiltration, interstitial fibrosis, and collagen accumulation in the SL. Similarly, there were mononuclear cell infiltration and interstitial fibrosis in the SL in the ketamine-recovery group (Figure 2C). However, the ketamine-HA-treated bladders exhibited significant reduction in denuded urothelial mucosa, mononuclear cell infiltration, interstitial fibrosis, and collagen accumulation (Figure 2D).

The urothelial distributions of E-cadherin (adhesion protein) and claudin-4 (tight junction protein) are shown in Figure 2, E-H. In the control group, claudin-4 and E-cadherin double-labeling were distributed in intercellular junctions of the UL, whereas the SL showed no immunoreactivity for either claudin-4 or E-cadherin (Figure 2E). Moreover, the colabeling of claudin-4 and E-cadherin was restricted to the thinner and disrupted urothelium in the ketamine or the ketamine-recovery group (Figure 2, F and G). However, in the ketamine-HA group, the double staining in the urothelial microvillus was enhanced (Figure $2 \mathrm{H}$ ).

Furthermore, urothelial adhesion protein (E-cadherin), tight junction proteins (claudin-4 and ZO-1), and the differentiated marker of urothelial umbrella cells (UPKIII) were decreased significantly in the ketamine group compared with the control group (Figure 2, I and J). These markers in the ketamine-recovery and the ketamine-HA 


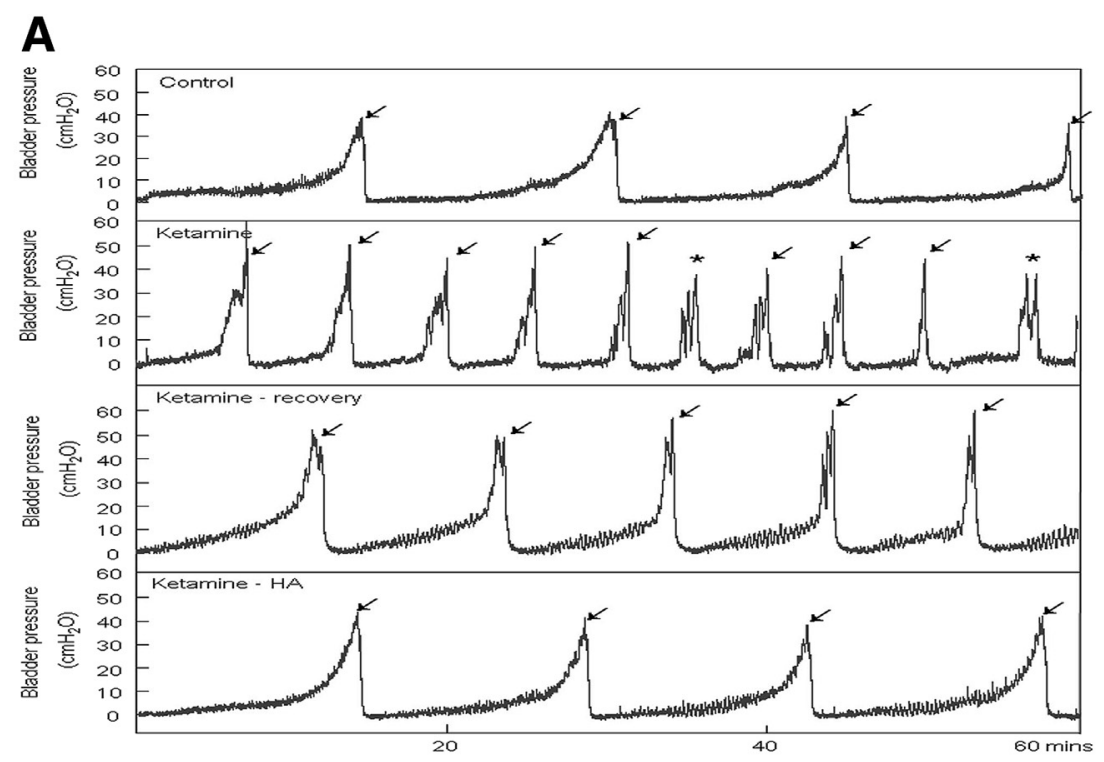

B

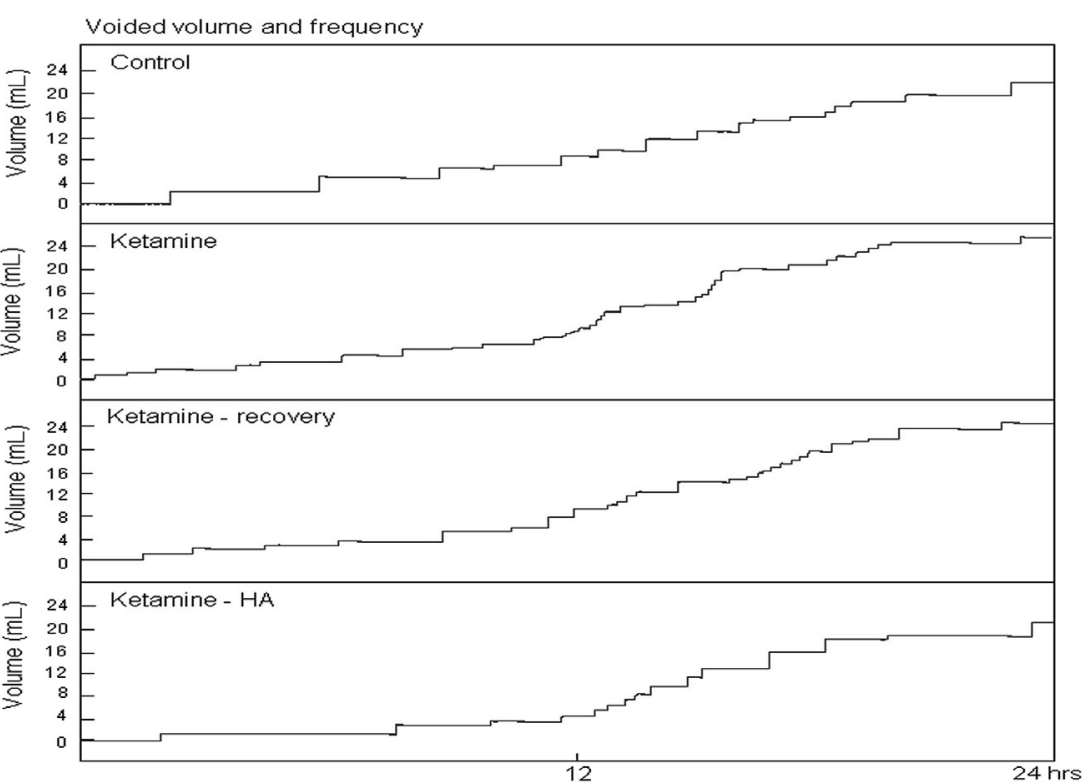

Figure 1 The effects of ketamine and hyaluronic acid (HA) instillation on bladder cystometric parameters and voiding behavior. A: Cystometric recordings illustrate micturation pressure and voiding frequency, including voiding contractions (arrows) and nonvoiding contractions (asterisks). B: Tracing analysis of 24-hour voiding behavior. The recordings demonstrate the ketamine group had significantly increased bladder micturation pressure, voiding contractions, nonvoiding contractions, and micturition frequency compared with the other groups. $n=8$ in each group (A and $\mathbf{B}$ ).

groups were increased significantly compared with the ketamine group. These observations demonstrated that ketamine administration reduced the expression level of urothelial barrier-associated protein, which might attribute to urothelial lining defects in KIC. Nevertheless, HA treatment improved ketamine-induced alterations in the urothelial junction-associated proteins in KIC.

The expression of inflammatory and fibrosis markers (COX-2, TGF- $\beta 1$, fibronectin, and type I collagen) at the protein level was examined (Figure 2, K and L). In comparison with the control group, the expression of COX-2 protein was increased by $593.6 \% \pm 76.5 \%$ in the ketamine group and $252.8 \% \pm 42.9 \%$ in the ketamine-recovery group compared with $105.8 \% \pm 14.2 \%$ in the ketamine-HA group. Similarly, the expression of TGF- $\beta 1$ protein was increased by $726.7 \% \pm 99.3 \%$ in the ketamine group and $156.8 \% \pm 28.5 \%$ in the ketamine-recovery group versus $99.6 \% \pm 13.9 \%$ in the ketamine-HA group. Moreover, the expression of fibronectin was enhanced by $488.3 \% \pm 64.4 \%$ in the ketamine group and $406.1 \% \pm 65.8 \%$ in the ketamine-recovery group compared with $181.6 \% \pm 15.6 \%$ in the ketamine-HA group. The expression of collagen I was increased by $302.7 \% \pm 42.8 \%$ in the ketamine group and $259.5 \% \pm 38.8 \%$ in the ketaminerecovery group versus $119.8 \% \pm 15.4 \%$ in the ketamineHA group. These observations implied that treatment in the ketamine and the ketamine-recovery groups significantly 


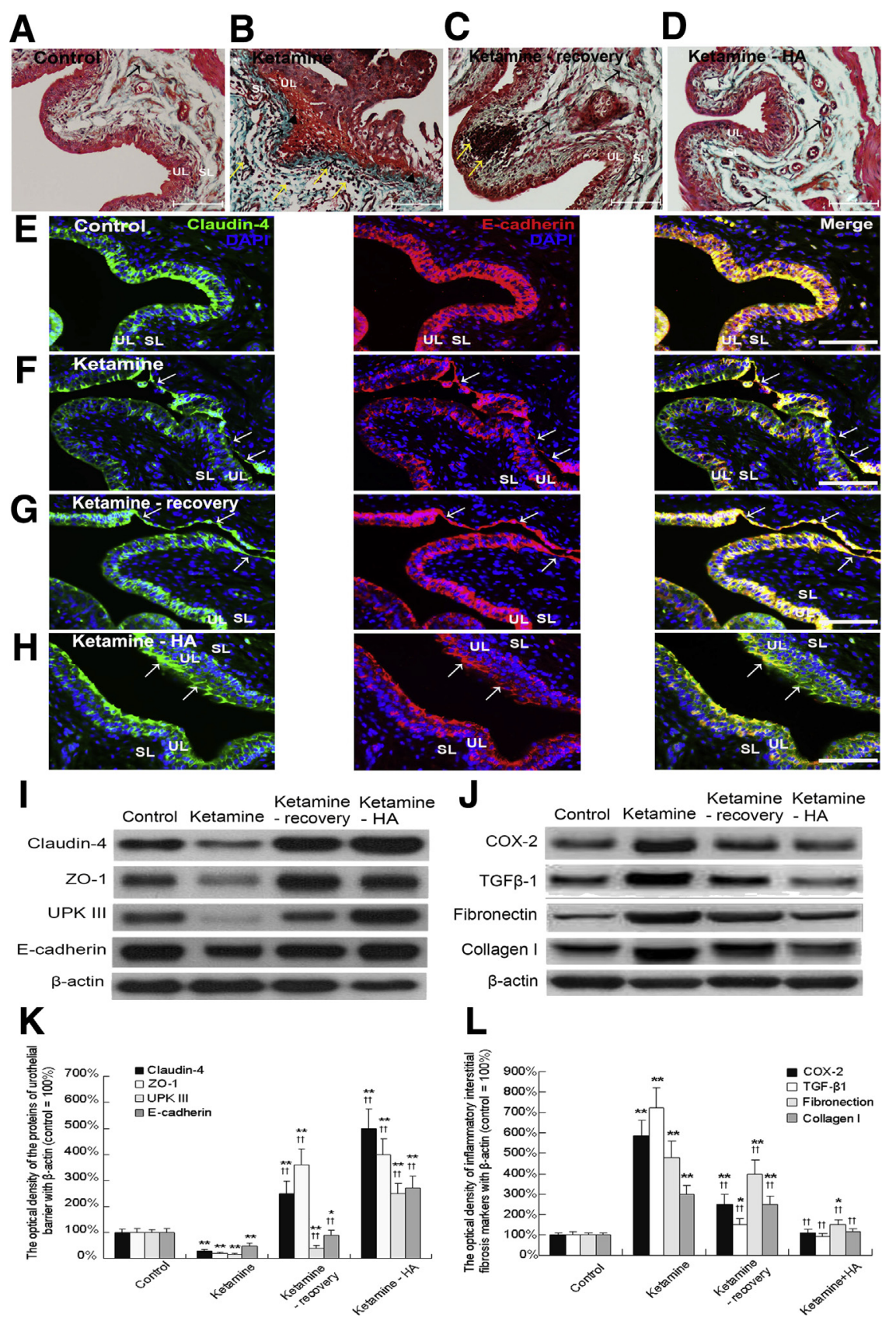

Figure 2 Hyaluronic acid (HA) improves the bladder pathologic feature and the expression of urothelial barrier proteins after ketamine and $\mathrm{HA}$ administration by Masson's trichrome stain. A-D: The ketamine group (B) indicates the increased mononuclear cell infiltration (yellow arrows) and collagen accumulation (black arrows) in the lamina propria of suburothelial layer (SL) and denuded urothelial mucosa (black arrowheads) compared with the control group (A). The ketamine-HA group (D) improves the above conditions, including mononuclear cell infiltration, interstitial fibrosis, and collagen accumulation (black arrows). E-H: Immunofluorescence stains reveal the expression of claudin- 4 and $\mathrm{E}$-cadherin proteins in bladder tissue. The immunoactivity of claudin- 4 (green) co-stained with E-cadherin (red) is expressed in the bladder urothelial layer (UL). These proteins were co-stained in the defective and thinning urothelium (arrows) in the ketamine group (F) and the ketamine-recovery group (G). HA treatment improves the disrupted urothelial barrier and increases the thickness of urothelium, which is restored to three to four layers $(\mathbf{H})$. I and $\mathrm{J}$ : The expression levels of tight junction proteins [claudin-4 and zonula occludens (Z0)-1], urothelial differentiation marker (UPKIII), and the adhesion protein (E-cadherin) were determined in the different groups by Western blot analysis. Quantification of the percentage of COX-2, TGF- $\beta 1$, fibronectin, and type I collagen expression to $\beta$ actin. $\mathbf{K}$ and $\mathbf{L}$ : Western blot analyses for inflammatory and fibrosis marker expression were measured by optical density of bladder tissue homogenate probed with an antibody specific to cyclooxygenase (COX)-2, transforming growth factor (TGF)- $\beta 1$, fibronectin, and type I collagen. Quantification of the percentage of each protein to $\beta$-actin is shown. Data are expressed as means \pm SD. $n=8$ in each group $(\mathbf{A}-\mathbf{L})$. ${ }^{*} P<0.05,{ }^{*} * P<0.01$ versus control; ${ }^{\dagger \dagger} P<0.01$ versus the ketamine group. Scale bars: $100 \mu \mathrm{m}$ $(A-H)$. Original magnification: $\times 400($ A-D). UPK, uroplakin. promoted bladder fibrotic biosynthesis, exacerbated bladder damage, and resulted in bladder interstitial fibrosis. In contrast, HA treatment reduced the fibrotic biosynthesis and ameliorated the bladder damage in KIC.

\section{mRNA Expression of the Receptors and Enzymes Involved in HA Synthesis and Degradation}

In consideration of the importance of HA metabolism in maintaining the integrity of bladder structure and function and tissue repair, we examined the mRNA levels of HA receptors, HASs, HYALs involving HA synthesis and degradation in the bladder ML and UL. The results showed that the mRNA expression of HA receptors was abundantly expressed in the ML but significantly declined in the UL in the ketamine group compared with the control group (Figure 3A) and such a level of HA receptor expression in the ML and the UL in the ketamine-recovery group (Figure 3A). On the contrary, in the ketamine-HA group, no noticeable change was found in HA receptor expression in the ML compared with the control group, but there was a 5.0-fold increase of such expression in the UL.

HASs were abundantly expressed in the ML and the UL of bladder tissues in the ketamine and the ketamine-recovery groups compared with the control group (Figure 3B). However, no significant increase in such expression was found in the ML in the ketamine-HA group; there was a 

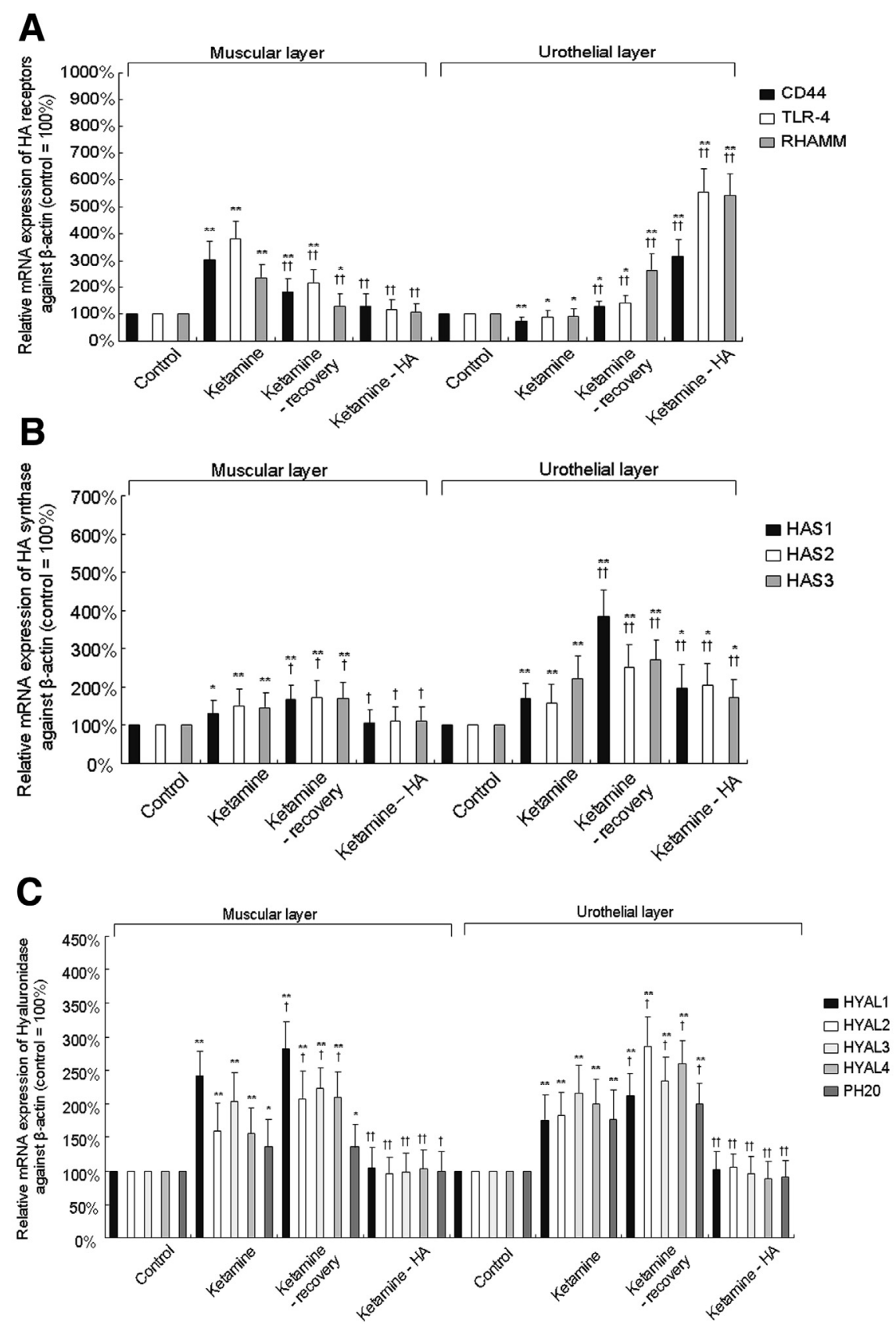

Figure 3 Real-time quantitative PCR of the mRNA levels of hyaluronic acid (HA) receptors [CD44, Toll-like receptor (TLR)-4, and receptor for HA-mediated motility (RHAMM); A], HA synthase (HAS)1 to HAS3 (B), and hyaluronidase [HYAL1 to HYAL4 and sperm adhesion molecule (PH20); C] involved in HA synthesis and degradation in bladder muscular layer (ML) and urothelial layer (UL). Data are expressed as means \pm SD. $n=8$ in each group (A-C). ${ }^{*}<0.05$, ${ }^{* *} P<0.01$ versus control; ${ }^{\dagger} P<0.05,{ }^{\dagger \dagger} P<0.01$ versus the ketamine group.

1.8-fold increase of HAS expression in the UL compared with the control group (Figure 3B). However, the expression of HYALs was 1.5 -fold higher in the ML and UL in the ketamine group, and 2.0-fold higher in the ketaminerecovery group compared with the control group. In contrast, no significant change was found in HYAL expression in the ML and UL of the ketamine-HA group (Figure 3C). These findings implied that ketamine induced HA receptor expression, activated HYAL expression, and altered HA metabolism, thus impairing bladder tissues in
KIC. HA instillation improved such ketamine-induced damages through modulating HA receptors and HASs.

Effect of Ketamine and HA Treatment on the Expression of Bladder-Associated Protein and HA Receptors

To examine bladder repair by HA instillation after ketamineinduced injury, the expression of E-cadherin, proliferation marker (Ki-67), UPKIII, and HA receptors was evaluated. 


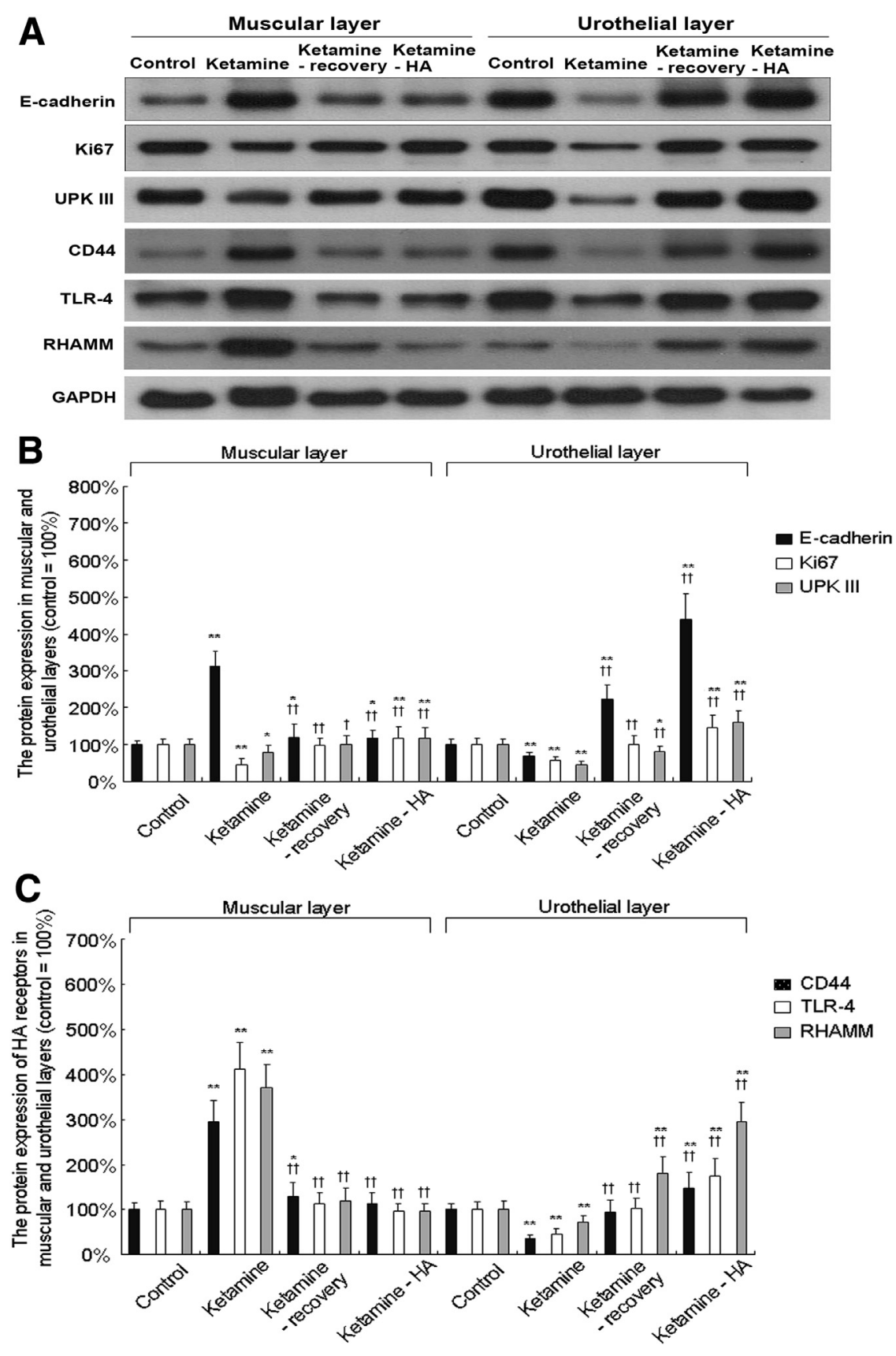

Figure 4 The expression of bladder repairassociated protein and hyaluronic acid (HA) receptors after ketamine and HA treatment. A: The protein levels of the adhesion protein (E-cadherin), proliferation marker (Ki-67), differentiation marker (UPKIII), and HA receptors [CD44, Toll-like receptor (TLR)-4, and receptor for HA-mediated motility (RHAMM)] were determined in the different groups by Western blot analysis. B: Protein level of UPKIII, Ki-67, and Ecadherin were investigated and normalized to the control group. C: The expression level of CD44, TLR-4, and RHAMM were determined and normalized to the control group. Data are expressed as means \pm SD. $n=8$ in each group $(\mathbf{A}-\mathbf{C}) .{ }^{*} P<0.05,{ }^{*} P<0.01$ versus control; ${ }^{\dagger} P<0.05,{ }^{\dagger \dagger} P<0.01$ versus the ketamine group. GAPDH, glyceraldehyde-3-phosphate dehydrogenase.

The results showed that the expression level of E-cadherin was significantly increased in the ML but declined in the UL in the ketamine group compared with the control group (Figure 4, A and B). The expression of Ki-67 and UPKIII was much lower in both the ML and UL in the ketamine group than in the control group (Figure 4, A and B). Nevertheless, in the ketamine-recovery group, their expression was markedly increased in both the ML and the UL compared with the ketamine group, but the increase was not as profound as in the control group (Figure 4, A and B). In addition, the protein level of Ki-67 and UPKIII was significantly increased in both the UL and the ML in the ketamine-HA group compared with the ketamine group (Figure 4, A and B).
Furthermore, the expression of HA receptors in the ketamine group were noticeably increased in the ML but decreased in the UL compared with the control group (Figure 4, A and C). In comparison with the control and the ketamine groups, the protein level of HA receptors was markedly increased in the UL of the ketamine-HA group but showed no significant changes in the ML. These findings suggested that ketamine induced abnormal differentiation of the ML and caused disruption of the UL, which might attribute to urothelial lining defects and result in alternation of matrix synthesis in the ML during the inflammation process of KIC. The effect of HA treatment on the ML and UL might play a crucial role on the restoration of bladder damage. 


\section{HA Treatment Improves Ketamine-Induced Alterations} in Urothelial Junction-Associated Protein Expression

To further explore the bladder damage after KIC injury and the bladder repair after HA treatment, the localization of $\mathrm{CD} 44$ and E-cadherin immunoreactivity was assessed (Figure 5, A-D). In the control group (Figure 5A), E-cadherin immunoactivity was detectable at intercellular junctions throughout the bladder urothelium, including apical, intermediate, and basal layers. However, CD44 immunolabeling was expressed in the plasma membranes of the basal layers of urothelium and in stroma cells in the lamina propria of the SL.

After ketamine treatment (Figure 5B), E-cadherin and CD44 proteins were strongly colabeled throughout the ulcerated and disrupted urothelium and stroma cells of the SL compared with the control group. In the ketaminerecovery group (Figure 5C), CD44 ${ }^{+}$cells were mainly expressed in the basal layer of urothelium and slightly stained in the lamina propria of the SL, and in some instances, $\mathrm{CD}_{4}{ }^{+}$cells colabeled with E-cadherin were distributed in all hyperplasia urothelium. However, in the ketamine-HA group, the $\mathrm{CD} 44^{+}$cells co-stained with
E-cadherin were strongly distributed in the basal layer of thickened urothelium layer (Figure 5D).

Furthermore, CK14, a specific marker of epithelial differentiation present in the basal layer of normal urothelium, was also examined. In the control group (Figure 5E), CD $44^{+}$cells were slightly co-stained with CK14 and mainly distributed in the basal layers of the urothelium. After ketamine treatment (Figure 5F), CD44 and CK14 proteins were strongly colabeled throughout the ulcerated and thinning urothelium compared with the control group. In the ketamine-recovery group (Figure $5 \mathrm{G}$ ), similar results for CK14 co-stained with CD44 were observed in the basal layer. However, in the ketamine-HA group, CD44 strongly co-stained with CK14 was mainly distributed in the basal layer of the proliferating urothelium and the suprabasal intermediate layer (Figure 5H). Similar results were obtained for the expression of TLR4 (Figure 6, A-D) and RHAMM (Figure 6, E-H). These results revealed that ketamine administration strongly induced the receptor expression of CD44 and TLR-4 and RHAMM in urothelial lining defects during the inflammation process of KIC. HA treatment improved ketamine-induced alterations and urothelial proliferation in response to ketamine injury.
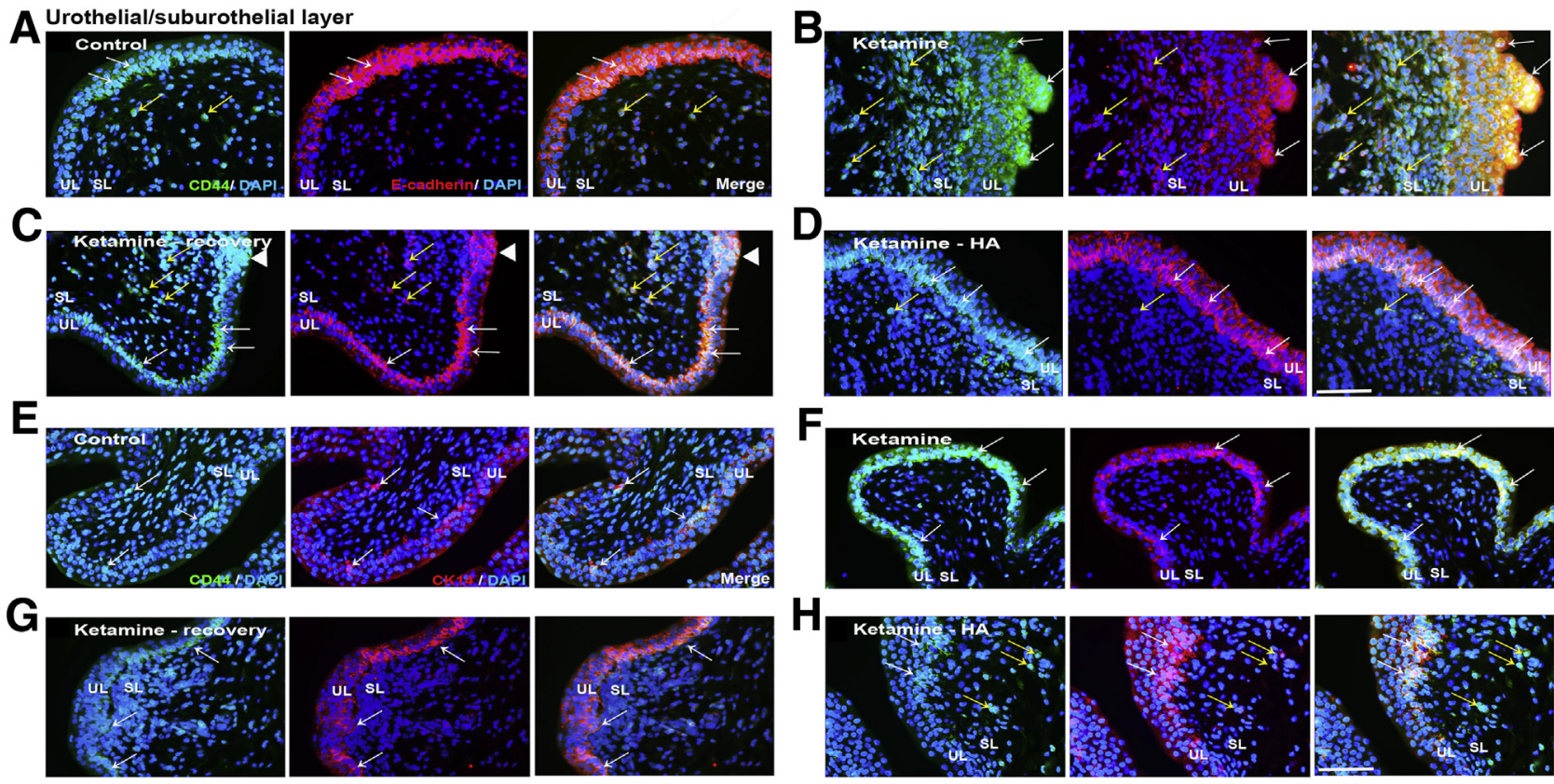

Figure 5 Immunofluorescence analysis of CD44 receptor, cytokeratin (CK)14, and E-cadherin after ketamine and hyaluronic acid (HA) treatments in the bladder. A: In the control group, E-cadherin staining (red) is seen at intercellular junctions throughout all urothelial layers (ULs). However, the CD44 expression (green) co-stained with E-cadherin is mainly distributed in the basal layer of the urothelium (white arrows). Slightly double staining was expressed in stromal cells (yellow arrows) of the suburothelial layer (SL). B: In the ketamine-treated group, E-cadherin colabeled with CD44 proteins is predominantly expressed throughout the ulcerated and disrupted urothelium (white arrows) and the stromal cells (yellow arrows) of the SL. C: In the ketamine-recovery group, $\mathrm{CD}_{4} 4^{+}$cells are mainly expressed in the basal layer (white arrows) and hyperplasia urothelium (white arrowheads) and are slightly stained in stroma cells (yellow arrows). D: In the ketamine-HA group, $\mathrm{CD}_{4} 4^{+}$cells co-stained with E-cadherin are strongly distributed in the basal and intermediate layers of the proliferating urothelium (white arrows). However, only weak double staining was expressed in stromal cells (yellow arrows). E: In the control group, CD44 expression (green) coincides with CK14 (red) and is mainly distributed in the basal layer of the urothelium. F: The ketamine group shows that CD44 ${ }^{+}$cells costained with CK14 are predominantly expressed throughout the thinning and repaired urothelium (white arrows) compared with the control group. G: In the ketamine-recovery group, $\mathrm{CD} 44^{+}$cells are mainly expressed in the basal layer (white arrows). $\mathrm{H}$ : In the ketamine-HA group, CD44 ${ }^{+}$cells co-stained with CD44 are strongly distributed in the basal layer of the proliferating urothelium (white arrows) and weak staining was shown in stromal cells (yellow arrows). Scale bars $=100 \mu \mathrm{m}(\mathbf{A}-\mathbf{H})$. Original magnification, $\times 400(\mathbf{A}-\mathbf{H})$. 


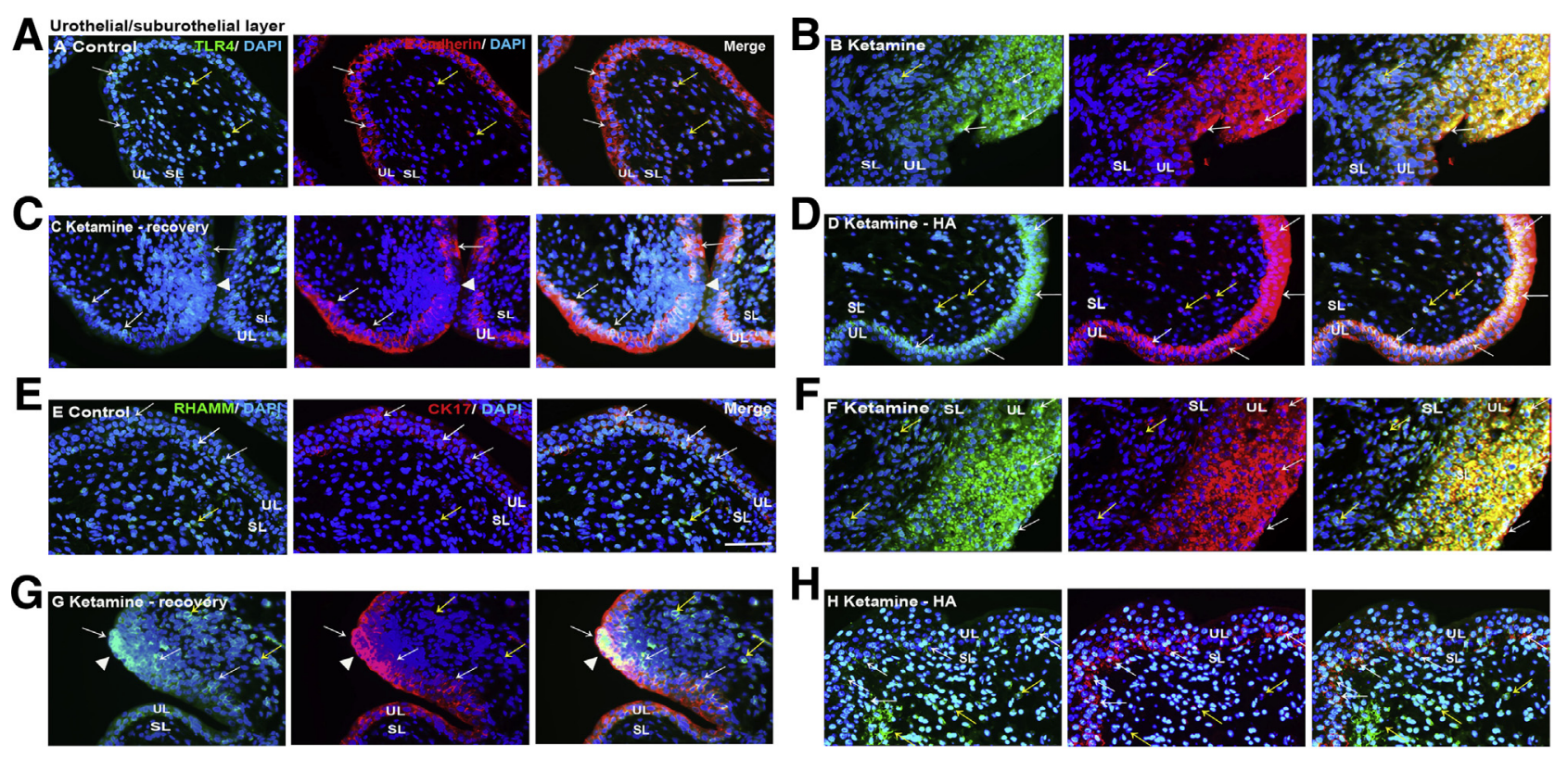

Figure 6 Immunofluorescence analysis for receptor Toll-like receptor (TLR)4 and receptor for hyaluronic acid (HA)-mediated motility (RHAMM) after ketamine and HA treatments in the bladder. A: In the control group, TLR4 expression (green) co-stains with E-cadherin and is mainly distributed in the basal layer of the urothelial layer (UL) (white arrows), and slightly co-labeled in stroma cells (yellow arrows). B: In the ketamine-treated group, TLR4 proteins are predominantly expressed throughout the ulcerated and disrupted urothelium (white arrows) and the stromal cells (yellow arrows) of the suburothelial layer (SL). C: In the ketamine-recovery group, TLR4 ${ }^{+}$cells are mainly expressed in the basal layer (white arrows) and hyperplasia urothelium (white arrowheads) and are slightly stained in stroma cells (yellow arrows). D: In the ketamine-HA group, $\mathrm{TLR}^{+}$cells are strongly distributed in the basal and intermediate layers (white arrows), slightly displayed in stroma cells (yellow arrows). E-H: Similar results were obtained for RHAMM expression coinciding with cytokeratin (CK) 17. The white arrows indicate double staining of RHAMM and CK17 in urothelium; yellow arrows, double staining in stroma cells. Scale bars $=100 \mu \mathrm{m}$ $(\mathbf{A}-\mathrm{H})$. Original magnification, $\times 400(\mathbf{A}-\mathbf{H})$.

From the above findings, a potential model was proposed for the mechanism of HA effect (Figure 7). The effect of HA instillation acted on the bladder in two manners in the treatment of KIC: HA receptor (CD44, RHAMM, and TLR-4) activation increased HAS enzymes and urothelial proliferation and differentiation, which resulted in urothelial restoration, and HA enhanced the matrix synthesis of stroma cells in SL and ML, which resulted in bladder remodeling.

\section{Discussion}

Treatment with ketamine in rats caused significant bladder hyperactivity with an increase in micturition frequency and bladder storage dysfunction. Moreover, ketamine administration decreased the expression of urothelial barrier-associated protein, induced abnormal urothelial differentiation, altered HA metabolism, and suppressed HA production, which might attribute to urothelial lining defects during the inflammatory process of KIC. On the contrary, HA instillation improved bladder hyperactivity and increased the expression of HA receptors (CD44, TLR-4, and RHAMM) and HA synthases (HAS1 to HAS3), leading to improving ketamine-induced bladder damage and enriching cell proliferation and differentiation in response to KIC injury.

Previous studies reported that intravesical HA instillation and/or chondroitin sulfate therapy improved the regeneration of the GAGs in patients with IC/PBS. ${ }^{40-43}$ Rooney et $\mathrm{al}^{44}$ demonstrated that HA decreased cytokine IL-6 and IL-8 secretion, increased GAG production, and decreased transepithelial permeability without altering tight junction expression. These reports suggested that the HA pathway was a clinical target and potential treatment vector for IC/PBS. In the present KIC animal study, HA instillations promoted the repair of the damaged GAG layer and enhanced bladder re-epithelialization and differentiation. The increased expression of adhesion protein (E-cadherin) along with a raise in tight junction protein (claudin-4 and ZO-1) expression suggested that HA restored urothelium impermeability.

HA is synthesized by synthases on the inner surface of the cell membrane and is extruded to the extracellular space. In patients with acute peripheral lung injury, there are significant increases in HA production. ${ }^{45}$ The expression of HAS2 mRNA is promoted in rats after radiation-induced lung injury, ${ }^{46}$ whereas blocking HA synthesis by HAS inhibitors can reduce enterotoxin-induced inflammation. ${ }^{47}$ HAS1 up-regulation is correlated with the level of HA synthesis during keratinocyte differentiation. ${ }^{48}$ In addition, HA was degraded into fragments after tissue injury ${ }^{49}$ by increasing the levels of HYALs and reactive oxygen species. ${ }^{50}$ The reactive oxygen species induced HYAL2 expression and thereafter generated HA fragments that contributed to lung fibrosis. ${ }^{46,51,52}$ Moreover, blockade of HA degradation with HYAL1 to HYAL3 siRNAs reduced CD44 expression and proinflammatory cytokines in mouse synovial fibroblasts after 


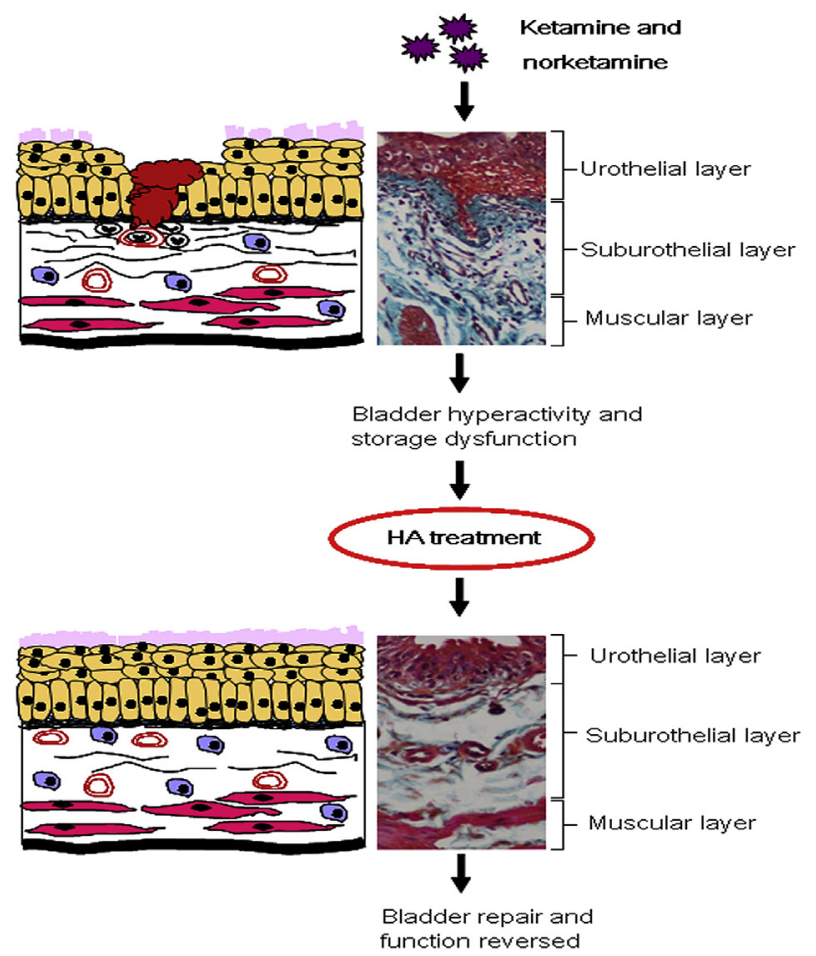

Figure 7 Proposed potential effect of hyaluronic acid (HA) instillation in ketamine-induced ulcerative cystitis. Ketamine treatment induces bladder damage, including i) pathologic changes: denuded urothelial mucosa, mononuclear cell infiltration, and interstitial fibrosis; ii) urothelial permeability defect: alterations in urothelial barrier-associated protein [claudin-4, zonula occludens-1, and uroplakin III (UPKIII)]; and iii) HA degradation: decrease in the level of hyaluronic acid synthase (Has)1 to Has3 and increase in the level of hyaluronidases (HYALS) and sperm adhesion molecule (PH20). HA improves ketamine-induced damage, including i) improved inflammatory injury; ii) modulated urothelial restoration: increase in urothelial proliferation $(\mathrm{Ki}-67)$ and differentiation (UPKIII), and enhanced adhesion protein (E-cadherin) synthesis; iii) increased HA synthesis: HA receptor activation (CD44, receptor for HAmediated motility, and Toll-like receptor-4), increase in the level of Has1 to Has3, and decrease in the level of HYALs and PH20. HA also promotes adhesion protein synthesis in the suburothelial and muscular layers, resulting in bladder remodeling.

collagen-induced arthritis. ${ }^{29}$ Our previous study demonstrated that ketamine increased oxidative stress generation mediated by endoplasmic reticulum- and mitochondria-dependent pathways and contributed to bladder urothelial defects. ${ }^{33}$ The present finding suggested that the up-regulation of HASs and HYALs in KIC might be necessary for the regulation of inflammation and HA biosynthesis for bladder repair. The mRNA expression of HYAL1 to HYAL4 and PH20 was significantly expressed in the bladder tissues in the ketamine and the ketamine-recovery groups. Specially, HYALs in UL and ML were more expressed for HA degradation in the ketamine-recovery group, which resulted in not fully restoring bladder damage. However, HA instillation reduced HYAL expression, and HA degradation may repair bladder tissue and promote cell proliferation and differentiation.

Recent studies have implicated a critical role of altering HA metabolism in the pathophysiology and the healing process of injured tissues. ${ }^{46,53,54}$ CD44, TLR, and RHAMM are major cell-surface HA binding proteins and widely expressed in many cell types. ${ }^{32}$ Transgenic mice with the expression of an antisense CD44 cDNA under the control of the keratin-5 promoter exhibited defective keratinocyte proliferation, indicating the role of CD44 in the regulation of keratinocyte proliferation in response to extracellular stimuli. ${ }^{25}$ Moreover, extracellular signalregulated kinase (ERK)-1 and ERK-2 activation and fibroblast migration/differentiation are defective during the repair of Rhamm-deficient skin wounds and result in aberrant granulation. These data demonstrated RHAMM as a regulator of CD44-ERK-1/2 fibroblast signaling was required for wound repair. ${ }^{55}$ In the present KIC animal model, the expression of HA receptors, HASs and HYALs, was significantly increased in bladder UL and SL in the ketamine and ketamine-recovery groups and resulted in the urothelial lining defects and interstitial fibrosis. Moreover, HYAL activation induced HA degradation, and HA fragments stimulated interstitial stroma cells and enhanced interstitial fibrosis and bladder hyperactivity. However, HA instillation increased the expression of HA receptors and HASs and decreased the expression of HYALs in the UL for urothelial regeneration and reduced interstitial fibrosis.

The TGF- $\beta$ family of cytokines, including TGF- $\beta$ and bone morphogenic proteins, plays crucial roles in the disease pathogenesis. TGF- $\beta 1$ signaling controls many cellular processes, including cell proliferation, differentiation, apoptosis, and epithelial-to-mesenchymal transition. ${ }^{56}$ TGF$\beta 1$-induced epithelial-to-mesenchymal transition has been implicated in pathologic states such as renal fibrosis through Erk activation. ${ }^{57,58}$ The TGF- $\beta$ /TGF- $\beta$ type 1 receptor signaling for lower urinary tract targets for pharmacologic therapy to improve bladder inflammation and reduce somatic sensitivity. COX-2 is inducible in response to inflammatory stimuli, cytokines, and mitogens, resulting in exaggerated prostaglandin release. In a chemical-induced hemorrhagic cystitis animal study, it was indicated that COX-2 expression was increased in the bladder, suggesting that COX-2 might play an important role in bladder inflammation. ${ }^{58}$ Our previous study demonstrated that the early stage of ketamine cystitis revealed that COX-2 was mainly synthesized by the macrophage. ${ }^{59}$ However, in the later phase of ketamine-induced inflammation, macrophages might produce other cytokines and were not completely colabeled with COX-2. ${ }^{59}$ The COX-2 up-regulation via the NF- $\kappa \mathrm{B}$ pathway was involved in the inflammatory signaling in KIC. ${ }^{60}$ The study suggested ketamine initiated the upregulation of COX- 2 and TGF- $\beta 1$ expression that might play an important role in contributing to ketamine-induced alterations in micturition patterns, ulcerative cystitis, and fibrosis. HA instillation decreased COX-2 and TGF- $\beta 1$ expression that modulated inflammatory responses, ameliorated bladder hyperactivity, and suppressed interstitial fibrosis in KIC. 
Our study revealed that the expression level of E-cadherin in the ketamine group was significantly increased in the ML but declined in the UL compared with the control group. In addition, E-cadherin was strongly labeled throughout the ulcerated and disrupted urothelium and stroma cells of the SL in the ketamine group compared with the control group. However, the level of E-cadherin was increased in the UL in the ketamine-recovery and ketamine-HA groups compared with the ketamine group. Therefore, likely urothelial cells within stromal compartment resulted from epithelium disruption and/or wound healing. The increased expression of E-cadherin was in coincidence with raising tight junction proteins and HA receptor expressions. Denudation or thinning of the epithelium and decreased urothelial proliferation have been noted in the IC/BPS bladder, suggesting an altered homeostasis in IC urothelium. ${ }^{61,62}$ E-cadherin concentration in the IC/BPS bladder urothelium was significantly lower than that of healthy controls. ${ }^{63}$ Ketamine treatment for human urothelial cells increased the TGF- $\beta 1$ expression and epithelial-to-mesenchymal transition-inducing transcription factors, resulting in the down-regulation of E-cadherin. ${ }^{64}$

In the present study, bladder differentiation was examined by protein UPKIII and CK14, and bladder proliferation was investigated by protein $\mathrm{Ki}-67$ and CD44 using immunofluorescence and Western blot analysis. In the ketamine group, the expression of Ki-67, UPKIII, and CD44 in the UL were much lower than in the control group. Moreover, the CD44 co-stained with CK14 was mainly distributed in the whole layer of the UL and the SL. In contrast, in the ketamine-HA groups, the expression of Ki-67, UPKIII, and CD44 in UL was markedly increased compared with the control and ketamine group, suggesting that ketamine induced abnormal ML differentiation and UL lining disruption, which might result in an alternation in bladder wall permeability during the inflammation process of KIC. HA instillation induced urothelial proliferation and differentiation and enhanced mucosal regeneration. These results implied that urothelial stem cells originate from basal urothelium, and urothelial repair after ketamine-induced injury would rely on proliferation of basal and intermediate cells. Future investigations would focus on obtaining the information about the regulation of bladder HA metabolism after ketamine addition.

\section{Conclusions}

Ketamine administration decreased the expression of urothelial barrier-associated proteins, induced abnormal urothelial differentiation, altered HA metabolism, and suppressed HA production. Such effects might contribute to urothelial lining defects during the inflammation process of KIC. HA instillation improved bladder hyperactivity and ketamine-induced bladder damage through increasing the expression of HA receptors and HA synthase and undergoing cell proliferation and differentiation in response to KIC injury.

\section{Acknowledgment}

We thank Prof. Chang-Hwei Chen (University at Albany, State University of New York) for valuable comments on this manuscript.

\section{References}

1. Middela S, Pearce I: Ketamine-induced vesicopathy: a literature review. Int J Clin Pract 2011, 65:27-30

2. Shahani R, Streutker C, Dickson B, Stewart RJ: Ketamine-associated ulcerative cystitis: a new clinical entity. Urology 2007, 69:810-812

3. Chen $\mathrm{CH}$, Lee MH, Chen YC, Lin MF: Ketamine-snorting associated cystitis. J Formos Med Assoc 2011, 110:787-791

4. Apodaca G: The uroepithelium: not just a passive barrier. Traffic 2004, 5:117-128

5. Sun TT, Liang FX, Wu XR: Uroplakins as markers of urothelial differentiation. Adv Exp Med Biol 1999, 462:7-18; discussion $103-114$

6. Acharya P, Beckel J, Ruiz WG, Wang E, Rojas R, Birder L, Apodaca G: Distribution of the tight junction proteins ZO-1, occludin, and claudin-4, -8 , and -12 in bladder epithelium. Am J Physiol Renal Physiol 2004, 287:F305-F318

7. Birder L, Andersson KE: Urothelial signaling. Physiol Rev 2013, 93 : 653-680

8. Parsons CL, Boychuk D, Jones S, Hurst R, Callahan H: Bladder surface glycosaminoglycans: an epithelial permeability barrier. J Urol 1990, 143:139-142

9. Fall M, Baranowski AP, Elneil S, Engeler D, Hughes J, Messelink EJ, Oberpenning F, de C Williams AC; European Association of Urology: EAU guidelines on chronic pelvic pain. Eur Urol 2010, 57: $35-48$

10. Parsons CL: The role of the urinary epithelium in the pathogenesis of interstitial cystitis/prostatitis/urethritis. Urology 2007, 69:9-16

11. Romih R, Korosec P, de Mello W Jr, Jezernik K: Differentiation of epithelial cells in the urinary tract. Cell Tissue Res 2005, 320: 259-268

12. Hicks RM, Ketterer B, Warren RC: The ultrastructure and chemistry of the luminal plasma membrane of the mammalian urinary bladder: a structure with low permeability to water and ions. Philos Trans R Soc Lond B Biol Sci 1974, 268:23-38

13. Martin BF: Cell replacement and differentiation in transitional epithelium: a histological and autoradiographic study of the guineapig bladder and ureter. J Anat 1972, 112:433-455

14. Kreft ME, Jezernik K, Kreft M, Romih R: Apical plasma membrane traffic in superficial cells of bladder urothelium. Ann N Y Acad Sci 2009, 1152:18-29

15. Kreft ME, Romih R, Kreft M, Jezernik K: Endocytotic activity of bladder superficial urothelial cells is inversely related to their differentiation stage. Differentiation 2009, 77:48-59

16. Lavelle J, Meyers S, Ramage R, Bastacky S, Doty D, Apodaca G, Zeidel ML: Bladder permeability barrier: recovery from selective injury of surface epithelial cells. Am J Physiol Renal Physiol 2002, 283:F242-F253

17. Reitinger S, Lepperdinger G: Hyaluronan, a ready choice to fuel regeneration: a mini-review. Gerontology 2013, 59:71-76

18. Chen WY, Abatangelo G: Functions of hyaluronan in wound repair. Wound Repair Regen 1999, 7:79-89

19. Croce MA, Dyne K, Boraldi F, Quaglino D Jr, Cetta G, Tiozzo R Pasquali Ronchetti I: Hyaluronan affects protein and collagen synthesis by in vitro human skin fibroblasts. Tissue Cell 2001, 33: 326-331

20. Xing G, Ren M, Verma A: Divergent temporal expression of hyaluronan metabolizing enzymes and receptors with craniotomy vs. 
controlled-cortical impact injury in rat brain: a pilot study. Front Neurol 2014, 5:173

21. Wisniewski HG, Hua JC, Poppers DM, Naime D, Vilcek J, Cronstein BN: TNF/IL-1-inducible protein TSG-6 potentiates plasmin inhibition by inter-alpha-inhibitor and exerts a strong antiinflammatory effect in vivo. J Immunol 1996, 156:1609-1615

22. Toole BP: Hyaluronan: from extracellular glue to pericellular cue. Nat Rev Cancer 2004, 4:528-539

23. Lee JY, Spicer AP: Hyaluronan: a multifunctional, megaDalton, stealth molecule. Curr Opin Cell Biol 2000, 12:581-586

24. Toole BP: Hyaluronan is not just a goo! J Clin Invest 2000, 106 : $335-336$

25. Kaya G, Rodriguez I, Jorcano JL, Vassalli P, Stamenkovic I: Selective suppression of CD44 in keratinocytes of mice bearing an antisense CD44 transgene driven by a tissue-specific promoter disrupts hyaluronate metabolism in the skin and impairs keratinocyte proliferation. Genes Dev 1997, 11:996-1007

26. Jiang D, Liang J, Fan J, Yu S, Chen S, Luo Y, Prestwich GD, Mascarenhas MM, Garg HG, Quinn DA, Homer RJ, Goldstein DR, Bucala R, Lee PJ, Medzhitov R, Noble PW: Regulation of lung injury and repair by Toll-like receptors and hyaluronan. Nat Med 2005, 11:1173-1179

27. Zaman A, Cui Z, Foley JP, Zhao H, Grimm PC, Delisser HM, Savani RC: Expression and role of the hyaluronan receptor RHAMM in inflammation after bleomycin injury. Am J Respir Cell Mol Biol 2005, 33:447-454

28. Mondalek FG, Fung KM, Yang Q, Wu W, Lu W, Palmer BW, Frimberger DC, Greenwood-Van Meerveld B, Hurst RE, Kropp BP, Lin HK: Temporal expression of hyaluronic acid and hyaluronic acid receptors in a porcine small intestinal submucosa-augmented rat bladder regeneration model. World J Urol 2015, 33:1119-1128

29. Campo GM, Avenoso A, D’Ascola A, Scuruchi M, Prestipino V, Nastasi G, Calatroni A, Campo S: The inhibition of hyaluronan degradation reduced pro-inflammatory cytokines in mouse synovial fibroblasts subjected to collagen-induced arthritis. J Cell Biochem 2012, 113:1852-1867

30. Trabucchi E, Pallotta S, Morini M, Corsi F, Franceschini R, Casiraghi A, Pravettoni A, Foschi D, Minghetti P: Low molecular weight hyaluronic acid prevents oxygen free radical damage to granulation tissue during wound healing. Int J Tissue React 2002, 24:65-71

31. Moseley R, Leaver M, Walker M, Waddington RJ, Parsons D, Chen WY, Embery G: Comparison of the antioxidant properties of HYAFF-11p75, AQUACEL and hyaluronan towards reactive oxygen species in vitro. Biomaterials 2002, 23:2255-2264

32. Jiang D, Liang J, Noble PW: Hyaluronan as an immune regulator in human diseases. Physiol Rev 2011, 91:221-264

33. Liu KM, Chuang SM, Long CY, Lee YL, Wang CC, Lu MC, Lin RJ, Lu JH, Jang MY, Wu WJ, Ho WT, Juan YS: Ketamine-induced ulcerative cystitis and bladder apoptosis involve oxidative stress mediated by mitochondria and the endoplasmic reticulum. Am J Physiol Renal Physiol 2015, 309:F318-F331

34. Herrera GM, Meredith AL: Diurnal variation in urodynamics of rat. PLoS One 2010, 5:e12298

35. Cottrell A, Warren K, Ayres R, Weinstock P, Kumar V, Gillatt D: The destruction of the lower urinary tract by ketamine abuse: a new syndrome? BJU Int 2008, 102:1178-1179; author reply 9

36. Yuan JS, Reed A, Chen F, Stewart CN Jr: Statistical analysis of realtime PCR data. BMC Bioinformatics 2006, 7:85

37. Juan YS, Chuang SM, Lee YL, Long CY, Wu TH, Chang WC, Levin RM, Liu KM, Huang CH: Green tea catechins decrease oxidative stress in surgical menopause-induced overactive bladder in a rat model. BJU Int 2012, 110:E236-E244

38. Juan YS, Chuang SM, Long CY, Chen CH, Levin RM, Liu KM, Huang $\mathrm{CH}$ : Neuroprotection of green tea catechins on surgical menopause-induced overactive bladder in a rat model. Menopause 2012, 19:346-354

39. Alameda F, Juanpere N, Pijuan L, Lloveras B, Gimeno J, Baro T, Salido M, Serrano S, Lloreta J: Value of p16(INK4a) in the diagnosis of low-grade urothelial carcinoma of the urinary bladder in urinary cytology. Cancer Cytopathol 2012, 120:276-282

40. Gulpinar O, Kayis A, Suer E, Gokce MI, Guclu AG, Arikan N: Clinical comparision of intravesical hyaluronic acid and hyaluronic acid-chondroitin sulphate therapy for patients with bladder pain syndrome/interstitial cystitis. Can Urol Assoc J 2014, 8:E610-E614

41. Cervigni M, Natale F, Nasta L, Padoa A, Voi RL, Porru D: A combined intravesical therapy with hyaluronic acid and chondroitin for refractory painful bladder syndrome/interstitial cystitis. Int Urogynecol J Pelvic Floor Dysfunct 2008, 19:943-947

42. Porru D, Leva F, Parmigiani A, Barletta D, Choussos D, Gardella B, Dacco MD, Nappi RE, Allegri M, Tinelli C, Bianchi CM, Spinillo A, Rovereto B: Impact of intravesical hyaluronic acid and chondroitin sulfate on bladder pain syndrome/interstitial cystitis. Int Urogynecol J 2012, 23:1193-1199

43. Giberti C, Gallo F, Cortese P, Schenone M: Combined intravesical sodium hyaluronate/chondroitin sulfate therapy for interstitial cystitis/bladder pain syndrome: a prospective study. Ther Adv Urol 2013, 5:175-179

44. Rooney P, Srivastava A, Watson L, Quinlan LR, Pandit A: Hyaluronic acid decreases IL-6 and IL- 8 secretion and permeability in an inflammatory model of interstitial cystitis. Acta Biomater 2015, 19: $66-75$

45. Schmidt EP, Li G, Li L, Fu L, Yang Y, Overdier KH, Douglas IS, Linhardt RJ: The circulating glycosaminoglycan signature of respiratory failure in critically ill adults. J Biol Chem 2014, 289: 8194-8202

46. Li Y, Rahmanian M, Widstrom C, Lepperdinger G, Frost GI, Heldin P: Irradiation-induced expression of hyaluronan (HA) synthase 2 and hyaluronidase 2 genes in rat lung tissue accompanies active turnover of HA and induction of types I and III collagen gene expression. Am J Respir Cell Mol Biol 2000, 23:411-418

47. McKallip RJ, Hagele HF, Uchakina ON: Treatment with the hyaluronic acid synthesis inhibitor 4-methylumbelliferone suppresses SEB-induced lung inflammation. Toxins 2013, 5:1814-1826

48. Malaisse J, Bourguignon V, De Vuyst E, Lambert de Rouvroit C, Nikkels AF, Flamion B, Poumay Y: Hyaluronan metabolism in human keratinocytes and atopic dermatitis skin is driven by a balance of hyaluronan synthases 1 and 3. J Invest Dermatol 2014, 134: $2174-2182$

49. Averbeck M, Gebhardt CA, Voigt S, Beilharz S, Anderegg U, Termeer CC, Sleeman JP, Simon JC: Differential regulation of hyaluronan metabolism in the epidermal and dermal compartments of human skin by UVB irradiation. J Invest Dermatol 2007, 127:687-697

50. Soltes L, Mendichi R, Kogan G, Schiller J, Stankovska M, Arnhold J: Degradative action of reactive oxygen species on hyaluronan. Biomacromolecules 2006, 7:659-668

51. Forteza RM, Casalino-Matsuda SM, Falcon NS, Valencia Gattas M, Monzon ME: Hyaluronan and layilin mediate loss of airway epithelial barrier function induced by cigarette smoke by decreasing E-cadherin. J Biol Chem 2012, 287:42288-42298

52. Lepperdinger G, Strobl B, Kreil G: HYAL2, a human gene expressed in many cells, encodes a lysosomal hyaluronidase with a novel type of specificity. J Biol Chem 1998, 273:22466-22470

53. Tammi R, Pasonen-Seppanen S, Kolehmainen E, Tammi M: Hyaluronan synthase induction and hyaluronan accumulation in mouse epidermis following skin injury. J Invest Dermatol 2005, 124: 898-905

54. Yung S, Thomas GJ, Davies M: Induction of hyaluronan metabolism after mechanical injury of human peritoneal mesothelial cells in vitro. Kidney Int 2000, 58:1953-1962

55. Tolg C, Hamilton SR, Nakrieko KA, Kooshesh F, Walton P, McCarthy JB, Bissell MJ, Turley EA: Rhamm-/- fibroblasts are defective in CD44-mediated ERK1,2 motogenic signaling, leading to defective skin wound repair. J Cell Biol 2006, 175:1017-1028

56. Shi Y, Massague J: Mechanisms of TGF-beta signaling from cell membrane to the nucleus. Cell 2003, 113:685-700 
57. Xie L, Law BK, Chytil AM, Brown KA, Aakre ME, Moses HL: Activation of the Erk pathway is required for TGF-beta1-induced EMT in vitro. Neoplasia 2004, 6:603-610

58. Hu VY, Malley S, Dattilio A, Folsom JB, Zvara P, Vizzard MA: COX-2 and prostanoid expression in micturition pathways after cyclophosphamide-induced cystitis in the rat. Am J Physiol Regul Integr Comp Physiol 2003, 284:R574-R585

59. Chuang SM, Liu KM, Li YL, Jang MY, Lee HH, Wu WJ, Chang WC, Levin RM, Juan YS: Dual involvements of cyclooxygenase and nitric oxide synthase expressions in ketamine-induced ulcerative cystitis in rat bladder. Neurourol Urodyn 2013, 32:1137-1143

60. Juan YS, Lee YL, Long CY, Wong JH, Jang MY, Lu JH, Wu WJ, Huang YS, Chang WC, Chuang SM: Translocation of NF-kappaB and expression of cyclooxygenase-2 are enhanced by ketamine-induced ulcerative cystitis in rat bladder. Am J Pathol 2015, $185: 2269-2285$
61. Shie JH, Kuo HC: Higher levels of cell apoptosis and abnormal Ecadherin expression in the urothelium are associated with inflammation in patients with interstitial cystitis/painful bladder syndrome. BJU Int 2011, 108:E136-E141

62. Hauser PJ, Dozmorov MG, Bane BL, Slobodov G, Culkin DJ, Hurst RE: Abnormal expression of differentiation related proteins and proteoglycan core proteins in the urothelium of patients with interstitial cystitis. J Urol 2008, 179:764-769

63. Lee CL, Jiang YH, Kuo HC: Increased apoptosis and suburothelial inflammation in patients with ketamine-related cystitis: a comparison with non-ulcerative interstitial cystitis and controls. BJU Int 2013, 112:1156-1162

64. Song L, Sen S, Sun YH, Zhou J, Mo L, He TH: Ketamine inhalation ameliorates ovalbumin-induced murine asthma by suppressing the epithelial-mesenchymal transition. Med Sci Monit 2016, 22: $2471-2483$ 